\title{
EDITORIAL
}

\section{¿FIN DE UN CICLO? DE LA GLOBALIZACIÓN AL PROTECCIONISMO Y LA NUEVA REARTICULACIÓN GEOESTRATÉGICA}

El periodo de la poscrisis se caracteriza por una prolongada recesión, falta de empleo, deflación de activos financieros, así como por la caída de los principales productos de exportación de las economías latinoamericanas. Se puede decir, que lo anterior, es el resultado de las políticas económicas implementadas durante más de cuatro décadas: apertura comercial, alianzas estratégicas de las grandes empresas transnacionales y el financiamiento de los inversionistas institucionales a toda actividad económica de gobierno.

Por otro lado, la democracia -como un régimen de gobernanza-, es en este momento, la expresión del ciudadano insatisfecho provocada por la caída de sus ingresos y por la falta de empleo, siendo las clases medias las que más se han visto afectadas al ser desplazadas por los cambios estructurales del sistema productivo y las nuevas tecnologías. La nueva generación de jóvenes en edad de trabajar no ha logrado obtener un empleo digno, lo que pone en juego los sistemas de pensiones y las inversiones en capital humano de una sociedad.

Hoy ha terminado un ciclo para América Latina con el fin de gobiernos progresistas, quienes hicieron un manejo de políticas sociales en beneficio de su población y cuya meta fue la disminución de la pobreza. La política social y el gasto en educación, salud y vivienda se transfiere al gasto de la deuda. Para poder crecer, los gobiernos recién llegados al poder han tenido que finiquitar los compromisos sociales para adecuarse a las necesidades de los mercados financieros. El regreso a los mercados internacionales y las expectativas de crecimiento económico, tanto para Argentina como para Brasil, han apostado a la profundización de políticas neoliberales y a una mayor inserción a los circuitos productivos en escala mundial. ¿Pueden funcionar estas políticas económicas ante el resultado de las recientes elecciones en Estados Unidos?

A partir del resultado de las votaciones en Estados Unidos y del tsunami provocado a nivel internacional por el triunfo del candidato Republicano, Donald Trump como su futuro presidente, es necesario reflexionar sobre las causas de dicho triunfo y el resultado de las políticas de cambio estructural de las últimas décadas. A ello se agrega la muerte de Fidel Castro, el fin de 
un proyecto revolucionario que signó el pensamiento económico, político y social de las luchas de liberación de los países subdesarrollados, cuestión que los gobiernos latinoamericanos deben tomar en cuenta.

El Tratado de Libre Comercio de América del Norte (TLCAN), punto central de la campaña de Trump, así como la necesidad de una nueva renegociación, ha tenido su efecto en el deslizamiento de la moneda mexicana (fluctuación del valor del peso frente al dólar). La oposición al Acuerdo Transpacífico de Cooperación Económica (TPP, por sus siglas en inglés) pone entre la espada y la pared al gobierno de Japón. Por otro lado, la regularización de la migración y la posible salida de indocumentados de Estados Unidos ha creado un "movimiento antimigración" que divide a ese país, cuyo origen es de grandes migraciones; no por ello-menos importante- la necesidad de fortalecer a través de una política fiscal el retorno de las empresas norteamericanas a Estados Unidos. El desdibujamiento de la globalización en aras de fortalecer y devolver el empleo a los estadounidenses, al igual que el Brexit y, las demandas no cumplidas por los partidos políticos en los gobiernos muestran insatisfacciones de la población en las campañas políticas.

De ahí el siguiente cuestionamiento: ¿̇hasta qué punto las promesas de campaña pueden ser realidad? En las últimas horas se han publicado innumerables noticias de lo que significaría acabar con el empleo de los mexicanos en Estados Unidos, así como el costo de llevar nuevamente las plantas industriales de China a ese país. A mediano plazo se verá si las promesas de campaña se harán realidad o si se subsumen a los intereses de los grandes corporativos que cotizan en Wall Street.

Es importante destacar lo que Atilio Borón ha señalado al hacer un análisis sobre quiénes le dieron el triunfo a Trump. Él dice que fue la población económicamente activa que en términos reales ha tenido sus salarios estancados, todos aquellos que han sido desplazados por las políticas de libre comercio y globalización.

La desigualdad social ha aumentado a tal grado que ha puesto en peligro la democracia, creando la necesidad de regímenes represivos, esto último ha sido señalado por James Galbraith y Joseph Stiglitz en innumerables foros a nivel internacional y plasmado en artículos y libros. Thomas Palley, en una carta abierta culpa a los gobernantes del fracaso de políticas de corte neoliberal en los dos periodos del Partido Demócrata. Sin darse cuenta, las promesas ofrecidas en su campaña fueron un fracaso que cedió el paso al triunfo del Partido Republicano, encabezado por un personaje que recogió las insatisfacciones de la mayoría de la población estadounidense. 
La democracia cobra fuerza porque se expresa en la oportunidad de los ciudadanos de manifestar los aciertos o desaciertos de las políticas de desarrollo encabezado por un gobierno a lo largo de un periodo de tiempo. Los resultados de las políticas económicas a nivel internacional representan la debilidad o fortaleza de un Estado frente al entorno internacional, así como su impacto en los ciudadanos. Por tanto, las expresiones de los estadounidenses a partir de las desigualdades ocasionadas por las políticas de desarrollo son expresadas en las elecciones en un régimen parlamentario. La relación de causalidad entre democracia, desarrollo y desigualdad da como resultado muchas veces lo inesperado.

Los ciudadanos del mundo no están satisfechos con la globalización, con las políticas neoliberales y con la disminución del empleo y el franco deterioro de los ingresos. Sin tomar a conciencia causas y efectos de los cambios estructurales a nivel mundial, la realidad del descontento muestra sus expresiones en las votaciones recientes, en naciones como: Argentina, Brasil, Perú y ahora Estados Unidos. Muy pronto, en el curso de los próximos dos años, veremos cambios importantes en las futuras elecciones democráticas del resto de los países latinoamericanos.

Este número abre con el artículo de Pierre Salama titulado Brasil y China: caminos de fortalezas y desconciertos, en el que el autor explica cómo la disminución del Producto Interno Bruto de Brasil no está relacionada con la caída del precio de sus productos de exportación, al disminuir la participación de China en la compra de las exportaciones brasileñas, sino más bien, en la falta de políticas económicas enfocadas a la inversión a nivel nacional. Las comparaciones entre China y Brasil a partir de los indicadores como Paridad del Poder Adquisitivo (PРA) y el Producto Interno Bruto (РІв) (entre 1980 y 2015), muestran que la falta de inversión, la profundización de reformas estructurales para reducir la pobreza, y una reforma fiscal profunda por parte del Estado han impedido una rápida recuperación después de la Gran Crisis a diferencia de China.

La transparencia de la deuda subnacional como mecanismo para limitar su crecimiento, cuyos autores son Marcela Astudillo, Andrés Blancas y Francisco Javier Fonseca Corona, introduce el tema de la transparencia al ámbito de las finanzas públicas abordando la corrupción y la rendición de cuentas. La importancia de la transparencia de los recursos incrementa la eficiencia y la distribución de la riqueza y fortalece el desarrollo de la democracia. Por tanto, la transparencia en el manejo de los recursos públicos y de la deuda pública se vuelve un elemento importante para enfrentar el incremento de déficits y 
el aumento de la deuda, ya que la corrupción afecta la composición del gasto público y distorsiona el sistema impositivo.

Lukasz Czarnecki en su trabajo: Problemáticas en la transición económica y sociodemográfica de México y Vietnam compara dos economías en transición hacia un modelo neoliberal que plantea retos importantes. Conocer las asimetrías y similitudes plasmadas en la Constitución de 1917 en México y en los lineamientos del Partido Comunista del Congreso de 1986 de Vietnam, permite entender las transiciones hacia políticas de mayor apertura al sector privado. En su momento ambos países tuvieron un alto grado de participación del Estado, pero paulatinamente la transformación hacia políticas de mercado debilitó el papel del mismo. Las desigualdades sociales siguen siendo más graves en México frente a Vietnam, según lo muestra el autor a través de los indicadores demográficos que presenta.

El artículo Crecimiento económico e industrialización en la Agenda 2030: perspectivas para México de Alejandra Trejo Nieto, profundiza en el marco de la Agenda, los Objetivos de Desarrollo Sustentable (oDs), centrándose en el 8: "Promover el crecimiento económico sostenido, inclusivo y sostenible, el empleo pleno y productivo y el trabajo decente para todos" y en el 9: "Construir infraestructuras resilientes, promover la industrialización inclusiva y sostenible y fomentar la innovación". La autora realiza un análisis basándose en los oDs 8 y 9 de la economía en México para realizar una crítica al bajo desempeño del crecimiento económico sin tomar la realidad mexicana y la apuesta del gobierno a políticas en el marco del Consenso de Washington.

Belem Vásquez y Salvador Corrales con su artículo: Industria del cemento en México: análisis de sus determinantes, señalan que la industria cementera es una de las más importantes en el país, no sólo porque expresa el ciclo económico, sino porque es un disparador en la dinámica del empleo y tiene un alto grado de sensibilidad en su relación con los precios a nivel nacional. Las grandes empresas en el ramo en México son parte de los grandes consorcios a nivel internacional, siendo Cemex una de las empresas mexicanas de mayor impacto en Estados Unidos. La caída de las ganancias a nivel internacional fue una expresión de la Gran Crisis en el sector de la construcción y la industria cementera.

El artículo de Issac Minian, Ángel Martínez y Jenny Ibáñez: Cambio tecnológico y relocalización de la industria del vestido, centra el análisis en la disminución de las exportaciones mexicanas de la industria del vestido y la quiebra de empresas estadounidenses con plantas en México a nivel mundial. Esta caída en las exportaciones es resultado de acuerdos comerciales, un menor valor agregado y la baja productividad frente a otros países a donde emigró la 
industria. Desde los años cincuenta, la industria textil inició la emigración a países de Asia, donde es muy difícil competir con salarios bajos.

¿Es necesaria una teoria multinivel del agente?: la perspectiva de Vernon Smith de Arturo Lara e Inti Barrientos analiza el comportamiento de los agentes pero fuera de la frontera tradicional de la economía. El diálogo entre distintas disciplinas permite, según Vernon Smith, una crítica a la teoría neoclásica y un mayor conocimiento de cómo los individuos adaptan su entorno. Por ello, insiste en que los alumnos lean más ciencia que economía. La propuesta de la neuroeconomía como una nueva subdisciplina es una gran aportación para profundizar en la humanomics.

Alicia Girón

La Dirección de la Revista Ciudad Universitaria, diciembre 2016 
